\title{
THE INFLUENCE OF SELECTED FACTORS ON THE STRENGHT OF WOOD ADHESIVE JOINTS
}

\section{Anna Rudawska' ${ }^{1}$, Marek Maziarz' ${ }^{1}$, Michał Šajgalík², Petr Valášek ${ }^{3}$, Tomas Zlamal ${ }^{4}$, Volodymyr lasnii ${ }^{5}$}

1 Lublin University of Technology, Faculty of Mechanical Engineering, ul. Nadbystrzycka 36, 20-618 Lublin, Poland,e-mail: a.rudawska@pollub.pl, marek.maziarz@pollub.edu.pl

2 University of Žilina, Faculty of Mechanical Engineering, Univerzitna 1, 010 26, Žilina, Slovakia, e-mail: michal. sajgalik@fstroj.uniza.sk

${ }^{3}$ Czech University of Life Science Prague, Faculty of Engineering, 165 21, Prague, Czech Republic, e-mail: valasek@tf.czu.cz

4 Technical University of Ostrava, Faculty of Mechanical Engineering, 17.listopadu 15, 70833 Ostrava - Poruba, Czech Republic, e-mail: tomas.zlamal@vsb.cz

5 Ternopil Ivan Puluj National Technical University, Faculty of Engineering of Machines, Structures and Technologies, Ruska str., 56, Ternopil, 46001, Ukraine, e-mail: v.iasnii@gmail.com

Received: 2018.05 .09

Accepted: 2018.06.09

Published: 2018.09.01

\begin{abstract}
This paper examines the effect of selected factors on the wood bonded joint strength. The structural factor under scrutiny was the geometry of the surface area; however, other major dimensions of adherends were compared as well. The tests were performed on 6 joint types: butt, v-shaped, interlocking, scarf, tongue \& groove, and single lap joints, which were formed on two types of substrate materials - pine and oak wood, and adhesively bonded. The joints were bonded with Prefere 6312 wood adhesive and Loctite 3430 two-component epoxy adhesive. Strength testing of the joints was performed on Zwick/Roell Z150 material testing machine, according to DIN EN 1465 standard. The results obtained from the tests indicate that bonded joints of oak wood exhibit higher strength properties than those of pine wood adherends, which was confirmed in nearly all strength tests.
\end{abstract}

Keywords: adhesive joint, strength, pine wood, oak wood.

\section{INTRODUCTION}

Adhesive bonding offers several important benefits over other joining techniques, such as: producing small-sized joints at a relatively low cost per piece, improvement of the visual aspect of the joint, high impenetrability of the joint, joining heterogeneous materials and lowweight joints $[1,11,17]$. Despite numerous advantages of adhesive joints, these can too fail. There is several failure mechanisms observed in adhesively bonded joints: adhesive/interfacial failure, cohesive failure in the adhesive or cohesive failure in the adherend [5]. The risk of failure, however, does not diminish the great practical applicability of adhesive bonding technology, as adhesive joints are rightly regarded as highly durable and are therefore long-established in different industries, including automotive, furniture or clothing industries $[1,12,22]$. Bonding of wood is also a key issue in the manufacturing of numerous wood products $[16,22]$. Especially regarding applications in the structural field, mechanical performance of wood-adhesive bonds is of fundamental importance. Apart from other influencing factors like adherend material, geometric design of the bond line and its loading conditions, the 
adhesive properties significantly impact the strength of an adhesive bond $[3,6,7,9,13$, 24]. The strength of adhesive joints is affected by a number of technological factors $[4,8,12$, $18,19,20,23]$, e.g. proper surface treatment, adhesive preparation, temperature and loading conditions during cure, and a few structural factors $[1,2,15,21]$, such as the type and thickness of adherends, overlap length, the type of joint, adhesive layer thickness. In order to improve the adhesive joint strength they are constantly subjected to a variety of tests that evaluate the impact of e.g. joint geometry, to determine the optimal joint type.

The aim of the present paper was to determine the impact of selected structural factors on the strength of adhesive joints of wood adherends based on the analysis of strength test results. The tests were conducted on 6 joint types of pine wood and 6 types of oak wood substrates, bonded by means of two tested adhesives. The analysed joint types were as follows: butt, v-shaped, interlocking, scarf, single-lap symmetrical and single lap joints.

\section{TEST METHODOLOGY}

\section{Substrate material and shape of specimens}

Two substrate materials were used in adhesive joints: pine and oak wood. The specimens were prepared for joining by means of different machinery and tools. The majority of specimens were produced with a milling machine equipped with a special cutting tool for a small-sized wood workpiece, nevertheless single-lap and butt joints did not require the application of the milling machine due to their simple geometry, and were produced with the hacksaw. The types of wood adhesive joints were presented in table 1 .

The example of one of wood adhesive joints was presented in Fig. 1 and the view of adherend was shown in Fig. 2.

The dimensions of butt adhesive joint (Fig. 1) were following: $\mathrm{H} 1=\mathrm{H} 2=19,38 \pm 0,02 \mathrm{~mm}, \mathrm{~B} 1=\mathrm{B} 2$ $=19,37 \pm 0,02 \mathrm{~mm}, \mathrm{~L} 1=\mathrm{L} 2=71,60 \pm 0,15 \mathrm{~mm}$ and $\mathrm{GS}=0,23 \pm 0,01 \mathrm{~mm}$

The adhesive joint design types under analysis slightly differed in dimensions, the geometry of the surface area and the cross-sectional area of the joint.

Table 1. The tested types of pine and oak wood adhesive joints

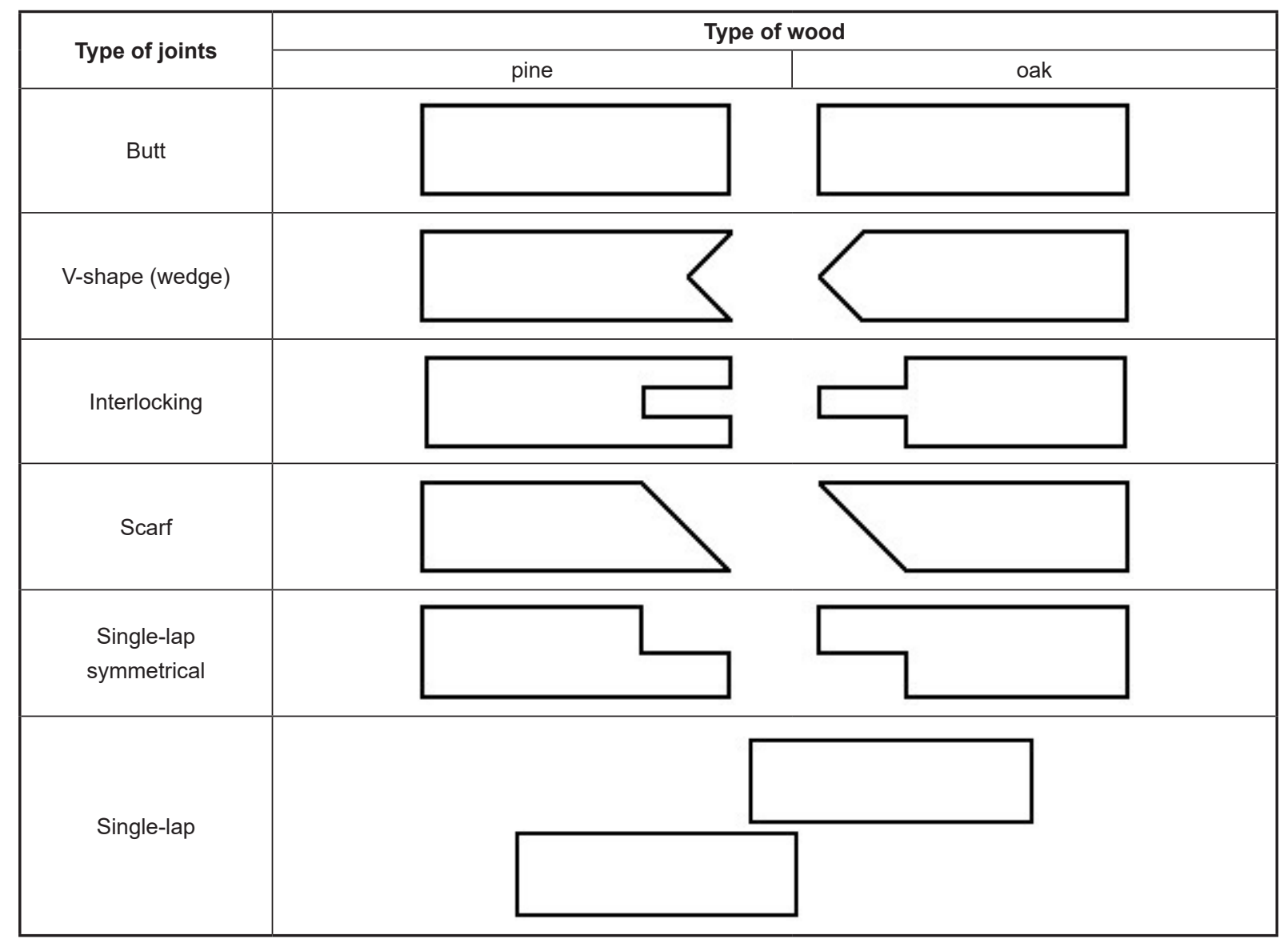



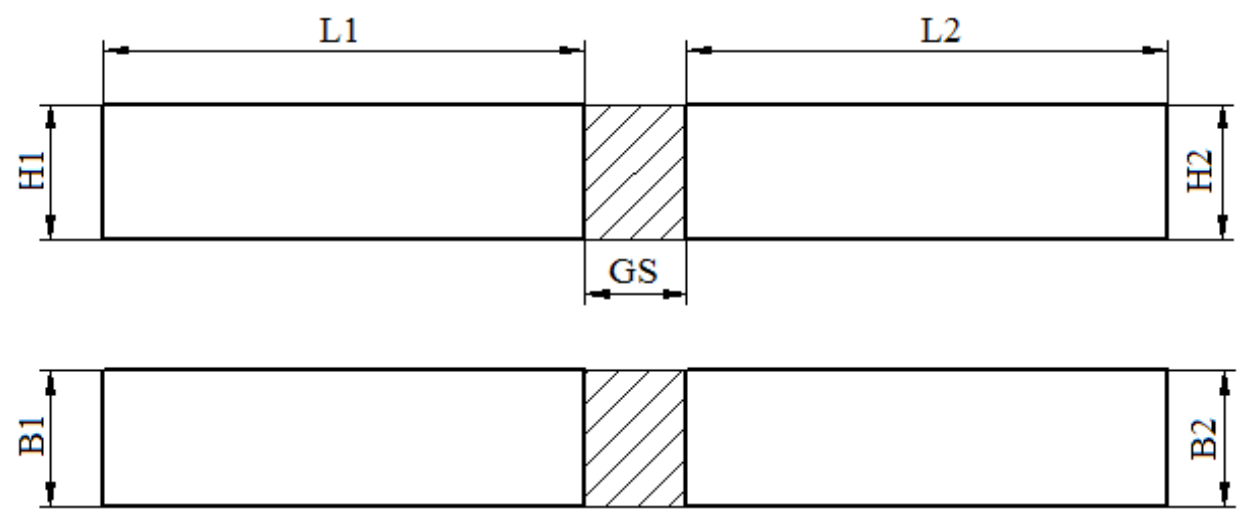

Fig. 1. Scheme of butt adhesive joint of pine wood: H1 and H2- high of adherends, B1 and B2 - width of adherends, L1 and L2 - length of adherends and GS - thickness of adhesive layer

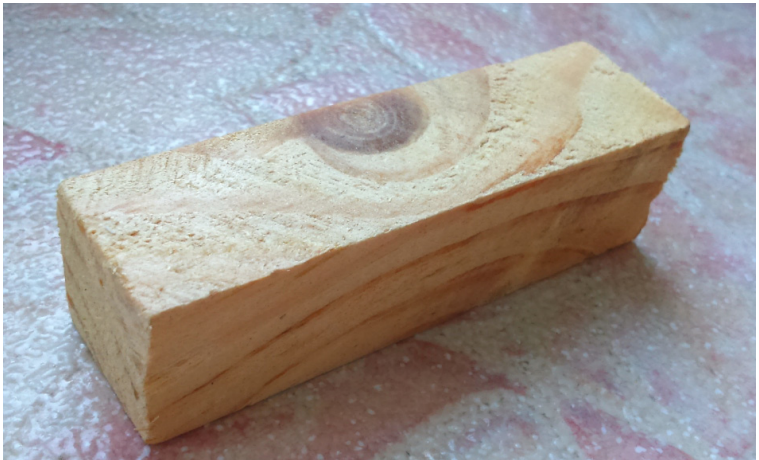

Fig. 2. Sample of pine wood

\section{Joint assembly conditions}

The strength tests were conducted on the total of 144 joint specimens, half of which were assembled with pine and the other half with oak adherends. All specimens created 72 joints, which were adhesively bonded with two types of adhesives: Loctite 3430 epoxy [14] and Prefere 6312 wood adhesive [15].
The specimens were prepared at the woodworking shop, equipped in the necessary tools and machinery.

Once the wooden specimens had been prepared, the wood chip contamination was removed from their surface in a two-fold process. First the surface was treated with the 100 and 180 grit sandpaper, and subsequently with the angle grinder.

The first stage of adhesive joining technology consisted in removing all contamination from the surface of adherends: the dust and wood swarf was brushed off the adherends.

Subsequently, the adhesives were prepared. While the single-component Prefere 6312 required no special preparation for the application, in the case of Loctite 3430 the resin and hardener had to be blended. Due to the short working life of the mixed adhesive the latter had to be prepared and applied on both adherends within a short time of mixing, not to exceed 5 minutes.

Prefere 6312 was applied with a brush on the surface of both adherends, due to locally ob-

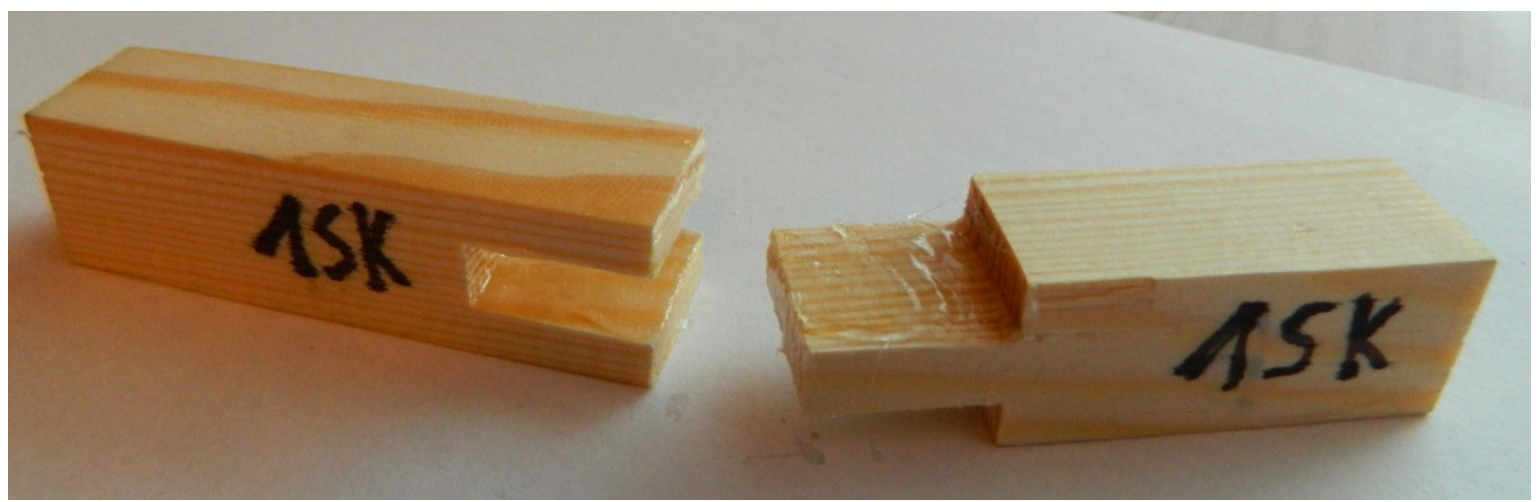

Fig. 3. Elements of the interlocking joint after application of Loctite 3430 


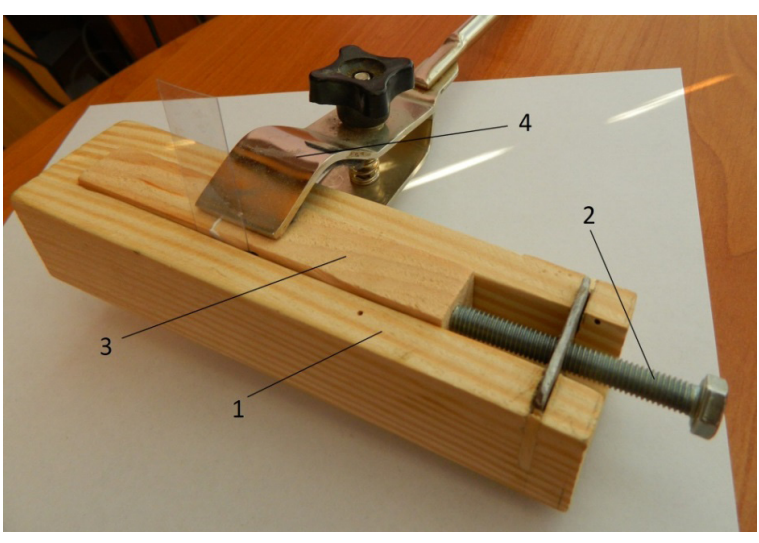

Fig. 4. Schematic representation of the locatingclamping tool for assembly and loading of adhesive: 1 - locating slot, 2 - set screw, 3 - scarf joint, 4 clamp

served high porosity of the substrate material. Immediately after the application of the adhesive, the adherends were assembled. Loctite $3430 \mathrm{ep}-$ oxy adhesive was applied on the adherend surface with the polymer adhesive spreader (Fig. 3).

After proper positioning and assembling the adherends, in certain cases it was necessary to remove the excess of the adhesive from the side surface of the joint. Subsequently, the load of $250 \mathrm{~N}$ was applied to the joint assembly with two clamping tools: the hand screw and a special locating-clamping tool. The correct position of joint elements was ensured with a jig with a locating slot and an additional set screw for applying pressure to the assembly (Fig. 4). The pressure applied by the screw in the locating slot was predominantly applied with the clamp, although in certain cases (the scarf joint) an additional hand screw was employed to prevent adherends from moving during adhesive cure. In the single lap joint the load during cure was applied by means of the clamp and the vice.

Each joint was subjected to loading for approximately 40 minutes, after which time both developed initial bond strength and was prepared for suitable post-curing processes.

The cure of the tested joint assemblies was conducted at a room temperature of approximately $23^{\circ} \mathrm{C}$ and $34 \%$ air humidity for 48 hours. According to the manufacturer's data, the adhesives develop the maximum strength after 24 hours' cure. The assembled specimens were subjected to destructive testing in the material testing machine after $48 \mathrm{~h}$, once the adhesive was assumed to be fully cured. The strength test was conducted in accordance with DIN EN [10].

\section{TEST RESULTS}

\section{Test results - Prefere 6312}

Fig. 5 collates the strength test results obtained from the destructive testing of both adherend types bonded with Prefere 6312 wood adhesive.

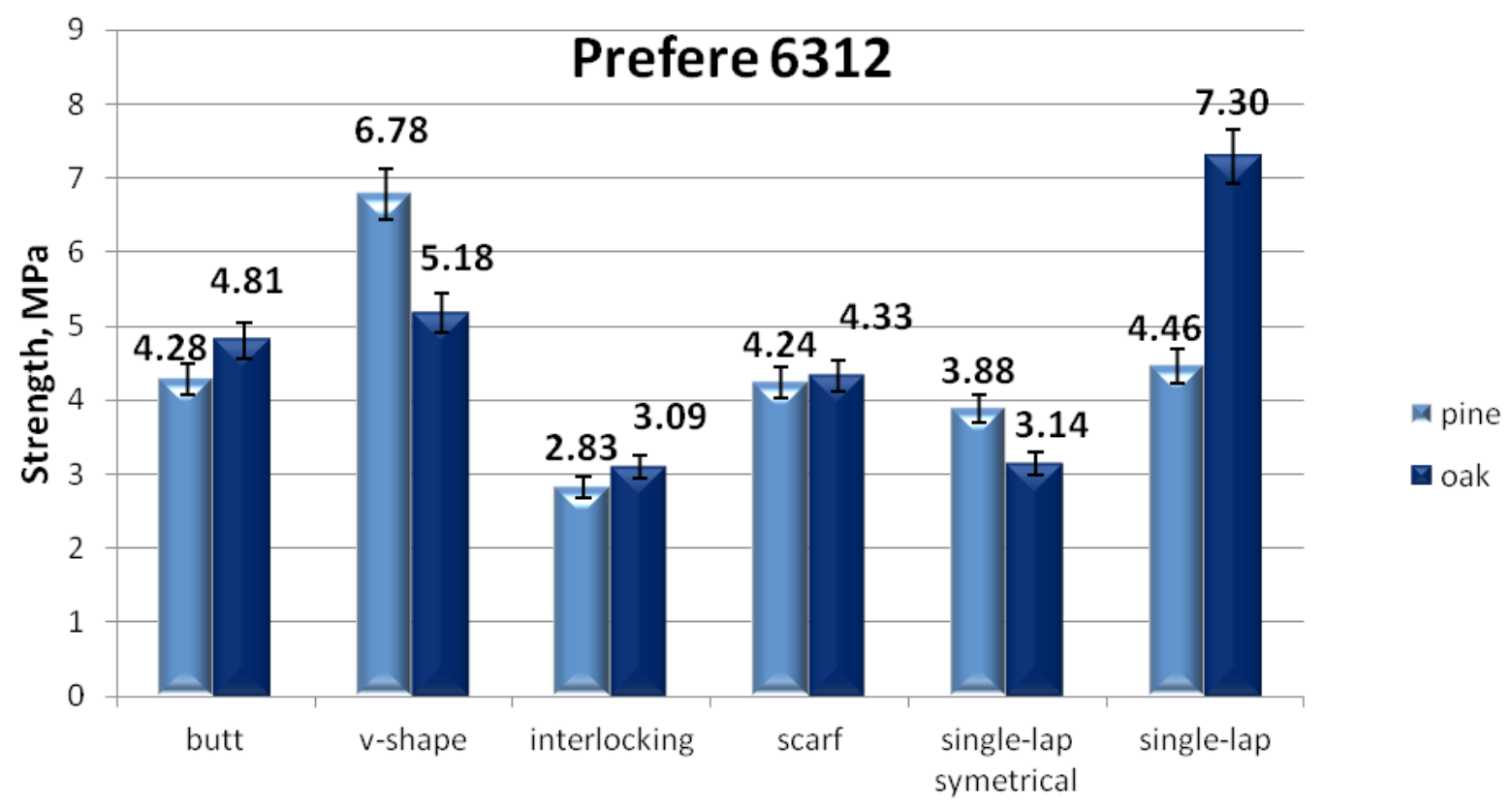

The type of adhesive joints

Fig. 5. Average adhesive joint strength of pine and oak wood adherends bonded with Prefere 6312 adhesive 


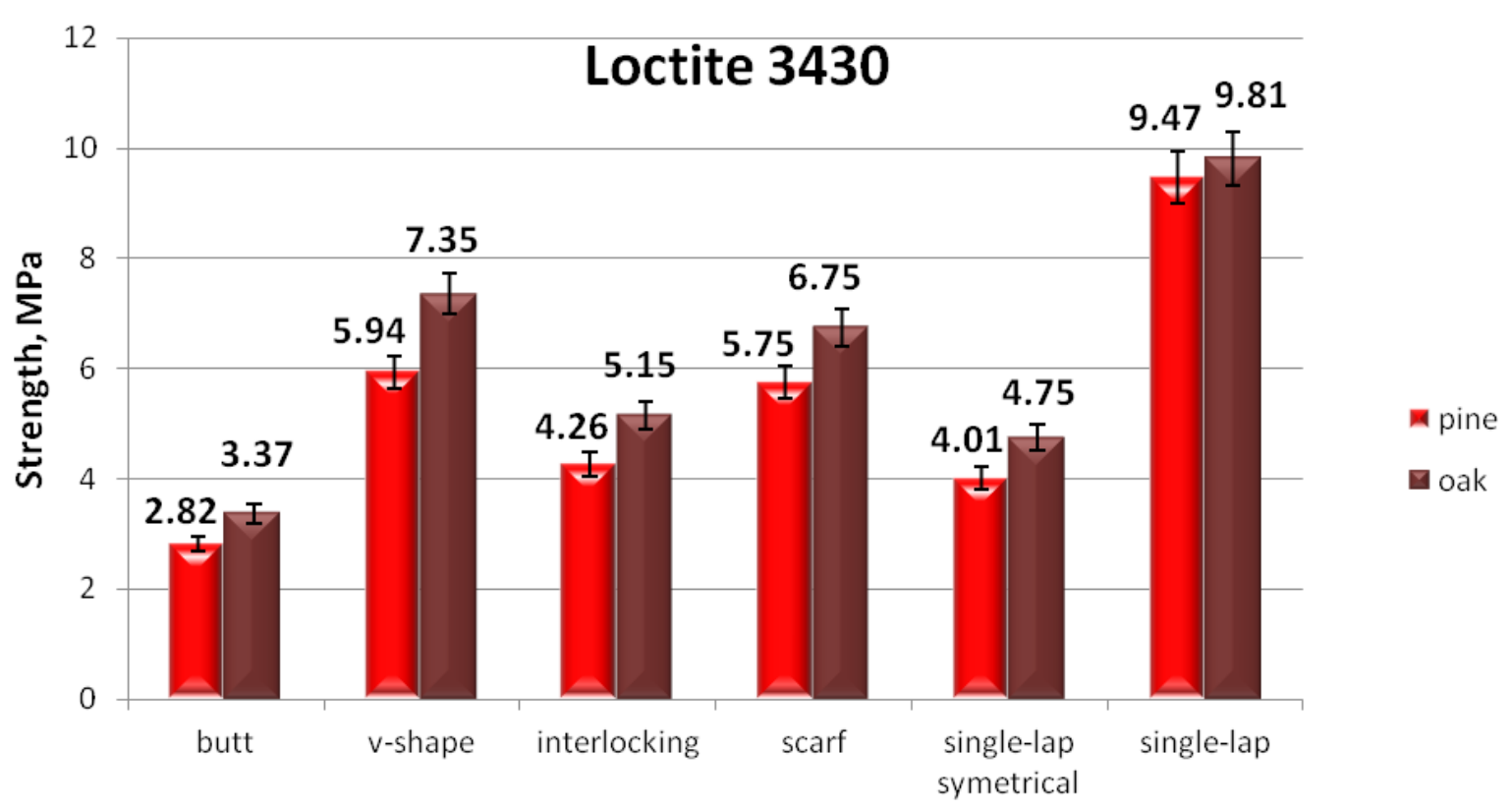

The type of adhesive joints

Fig. 6. Strength of pine wood adhesive joint bonded with Loctite 3430

The results shown in Fig. 5 indicate that for all pine wood joint assemblies the highest average joint strength was recorded in v-shaped joints, and was equal to $6.78 \mathrm{MPa}$, whereas the lowest strength was obtained in interlocking joints $(2.83$ $\mathrm{MPa}$ ). The difference between the two assemblies amounts to more than $50 \%$.

Among the oak wood adhesive joint assemblies subjected to tests the highest average strength was observed in single lap joints, where it amounted to $7.30 \mathrm{MPa}$, whereas the lowest strength was exhibited by interlocking joints: equal to $3.09 \mathrm{MPa}$. The difference between the extremes was $4.21 \mathrm{MPa}$, i.e. $58 \%$. It ought to be mentioned, however, that the difference in the cross-sectional area of the joints under test could have contributed to the discrepancies.

Interlocking adhesive joints provide the best exemplification of the observation as they required the application of failure load. Their average strength was equal to $2.83 \mathrm{MPa}$ (for the pine wood adherend), and $3.09 \mathrm{MPa}$ (for the oak wood) and results from the fact that the cross-sectional area of these joints were by far the highest and amounted to approximately $1200 \mathrm{~mm}^{2}$.

It is apparent from the results reported in Fig. 5 that in the majority of presented cases the oak wood adhesive joints exhibit higher strength than those of the pine wood adherend. The difference, however, is not significant because not all joint assembly types of oak wood showed superior strength. The highest difference between the average values of tensile strength detected in the tests was observed in single lap adhesive joints, where the oak wood adherend produced a $58 \%$ higher strength $(2.84 \mathrm{MPa})$ than the pine wood one. In scarf joints the observed discrepancy was the lowest $(0.09 \mathrm{MPa})$, and the pine wood adhesive joint exhibited $97 \%$ strength of the oak wood joint.

\section{Test results - Loctite 3430}

Fig. 6 collates strength test results conducted for different adhesive joint assemblies of pine and oak adherends, bonded with Loctite 3430 epoxy adhesive.

As shown in Fig. 6, all joint assembly types of the oak wood adherend bonded with Loctite 3430 are characterised by a slightly higher strength than the pine wood joints. The highest strength value difference was noted in the case of the v-shaped assembly, where the oak adherend joint exhibited tensile strength higher than the pine wood joint by 1.41 MPa; hence pine wood adhesive joint corresponded to $80 \%$ of the oak wood adhesive joint. The difference is slightly less notable in butt joints, where the difference of $0.55 \mathrm{MPa}$ indicates that the strength of the pine wood adhesive joint corresponds to $83 \%$ of the oak wood joint assembly.

However, it must be re-emphasised that the discrepancy in the performance between particular joint types results from the differences in the 


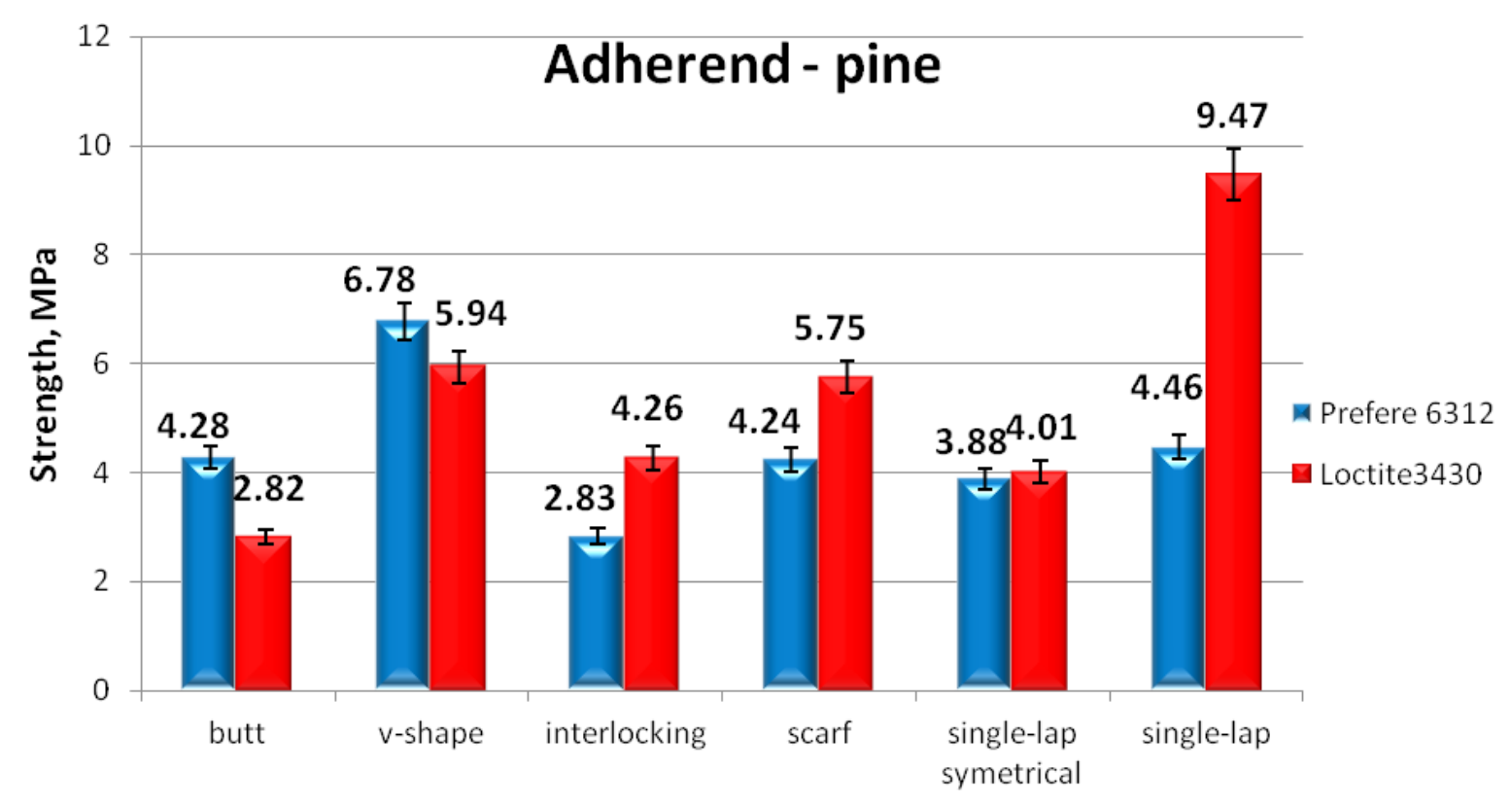

The type of adhesive joints

Fig. 7. The effect of the type of adhesive on the pine wood adhesive joint strength

cross-sectional area of the joint. The interlocking joints, for instance, required higher failure load, i.e. 4.26 MPa and 5.15 MPa for the pine wood and the oak wood adherend respectively. These results from the fact that the cross-sectional areas of the joint, of $1200 \mathrm{~mm}^{2}$, was incomparably higher than in all the other assemblies subjected to tensile testing.

\section{Results of comparative tests of adhesive joint strength of pine and oak wood adherends}

The results of the pine wood adhesive joint strength tests are collated in Fig. 7 and show the impact of the type of adhesive on the strength of the assembly.

The analysis of results collated in Fig. 7 indicates that Loctite 3430 produces higher strength joints (except for butt and v-shaped joints). In the majority of analysed cases higher load values were obtained by these assemblies rather than by Prefer 6312-bonded joints.

The most significant difference between the strength values measured for particular adhesive joint assemblies relative to the type of adhesive was observed in the single lap adhesive joint. The tests showed that single lap joints bonded with Loctite 3430 are characterised by higher strength than the corresponding joints bonded with Prefere 6312. The 5.01 MPa difference between two adhesives converts to a $47 \%$ drop in joint strength in the case of the latter adhesive. The lowest discrepancy between the joint strength of identical assemblies bonded with different adhesives was noted in tongue \& groove joints, where Loctite 3430 produced the bond that could withstand the load of 5.01 MPa higher than the Prefere 6312. Therefore, the strength of tongue $\&$ groove joints bonded with Prefere 6312 adhesive amounted to $96 \%$ of the strength obtained in tensile tests of assemblies bonded with Loctite 3430 .

It must be, nevertheless, re-emphasised that the discrepancy in the joint strength may be attributed to the difference in the cross-sectional area of particular adhesive joint assemblies.

The results of the oak wood adhesive joint strength tests are collated in Fig. 8, and show the impact of the type of adhesive on the strength of the assembly.

We observe from Fig. 8 that adhesive joints bonded with Loctite 3430 showed higher strength in all the analysed assemblies except for the butt joints. In the majority of tested configurations they demonstrated higher values than adhesive joints bonded with Prefere 6312 .

The most considerable difference between the values of strength obtained from the test was observed in the single lap joints bonded with Loctite 3430 , which exhibit strength higher by $2.51 \mathrm{MPa}$ than the joint assemblies bonded with Prefere 6312. This reveals that the strength of the lap ad- 


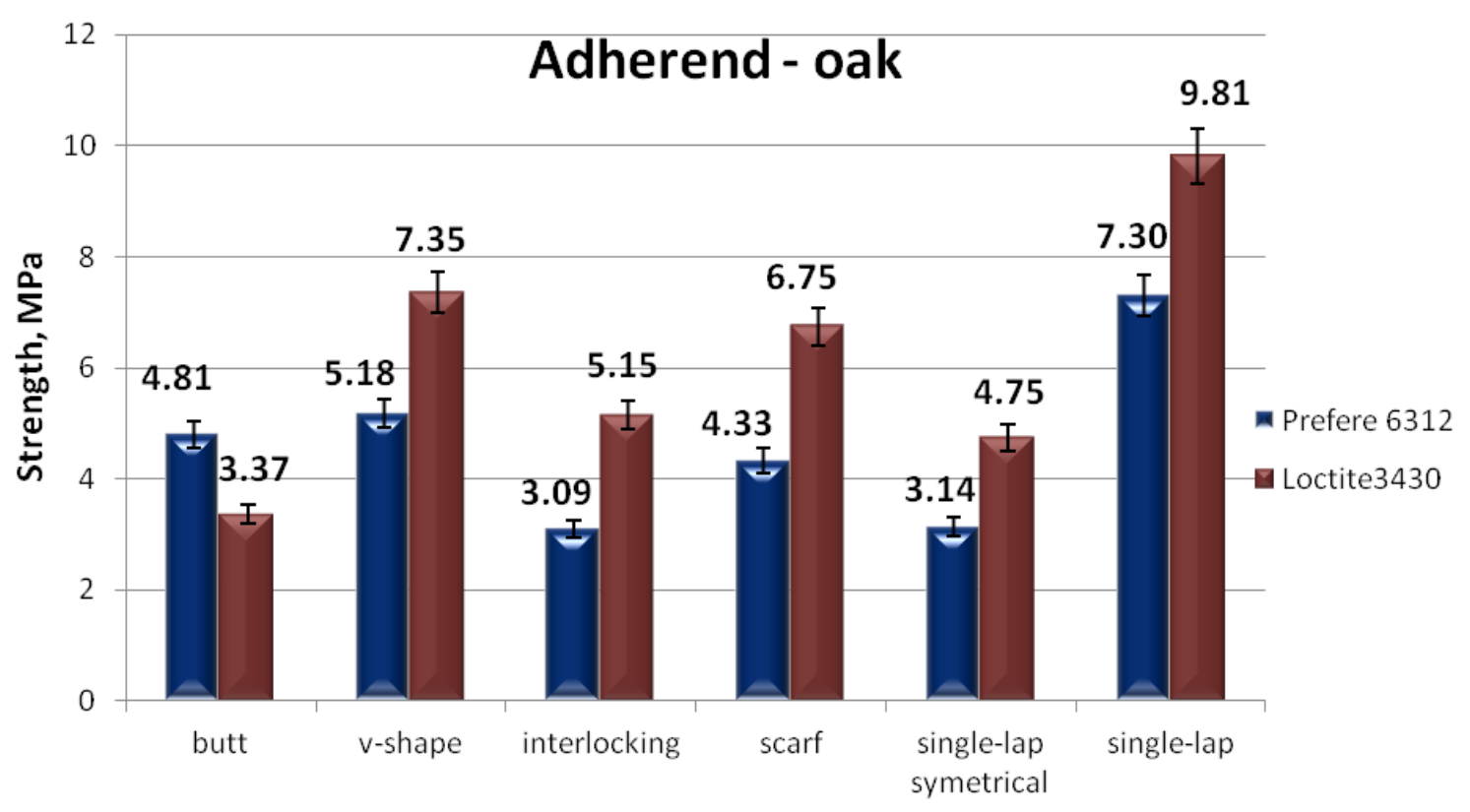

The type of adhesive joints

Fig. 8. The effect of the type of adhesive on the oak wood adhesive joint strength

hesive joints bonded with Prefere 6312 amounts to $74 \%$ of the joints bonded with Loctite 3430 . The lowest difference between the strength values, measured for particular tested joint assemblies, was recorded in tongue $\&$ groove joints. In the design in question it was Loctite 3430 adhesive that produced stronger joint than Prefere 6312, and the difference in these values amounted to $5.01 \mathrm{MPa}$. It therefore indicates that the latter adhesive forms the joint whose strength corresponds to $66 \%$ of the strength of the joint produced with Loctite 3430.

\section{CONCLUSIONS}

The evidence from the strength tests analysed in this paper, would seem to suggest that:

- Among the 6 types of the tested adhesive joint assemblies the highest failure load was recorded for the butt joint, which required the application of the highest failure load; simultaneously, the lowest failure load was obtained in the case of the butt joint assembly. The highest strength was demonstrated by the $\mathrm{v}$-shaped joint and the single lap joint, whereas the interlocking joint was found to be the weakest of all the tested joint designs. The scatter of strength test results was relatively wide, owing to the discrepancies in the cross-sectional area of the joints.

- The adhesive joint of the oak wood adherend demonstrates better strength properties than the pine wood adhesive joint. In nearly all tests the oak wood adhesive joint exhibited higher strength.

- Wood rarely succumbs to deformation and is therefore a highly durable material. This is confirmed by the results from the strength tests, where in all but one tested configurations the failure occurred in the adhesive layer (cohesive failure in the adhesive).

- In the majority of tested adhesive joint designs, regardless of the type of adherend, it was proven that the epoxy is a more suitable solution for adhesive bonding, as it produces joints of strength properties that are superior to those of the Prefere 6312.

The results obtained from the tests indicate that all operations involved in the technological process of adhesive joining should be carried out with utmost precision and care: from surface preparation to application of pressure during cure and observing the time required for the full cure of the adhesive. Furthermore, the strength of joints will be affected by a number of structural factors, including the shape/type of adhesive joints or the cross-sectional area of the joint.

\section{REFERENCES}

1. Adams R.D. (ed.). Adhesive bonding. Science, technology and applications. Woodhead Publishing, United Kingdom, 2010. 
2. Adams R.D., Comyn J. and Wake W.C. Structural Adhesive Joints in Engineering Book, 2nd edition, United Kingdom, Springer, 1997.

3. Bachtiar E.V., Clerc G., Brunner A.J., Kaliske M. and Niemz P. Static and dynamic tensile shear test of glued lap wooden joint with four different types of adhesives, International Journal of the Biology, Chemistry, Physics, and Technology of Wood, 5, 2017, DOI: https://doi. org/10.1515/hf-2016-0154.

4. Bławucki S. and Zaleski K. The Effect of the Aluminum Alloy Surface Roughness on the Restitution Coefficient. Advances in Science and Technology Research Journal, 9(27), 2015, 66-71.

5. BrockmannW., Geiß P.L., Klingen J. and Schröder B. Adhesive bonding. Materials, Applications and Technology, Weinheim, Germany, Wiley-Vch Press, 2009.

6. Conrad M.P.C., Smith G.D. and Fernlund G. Fracture of wood composites and wood-adhesive joints: A comparative review. Wood and Fibre Science, 1, 2004, 26-39.

7. Custódio J., Broughton J., Cruz H. and Winfield P. Activation of timber surface by flame and corona treatments to improve adhesion. International Journal of Adhesion and Adhesives, 29, 2009, 167-172.

8. Da Silva L.F.M., Carbas R.J.C., Critchlow G.W., Figueiredo M.A.V. and Brown K. Effect of material, geometry, surface treatment and environment on the shear strength of single lap joints. International Journal of Adhesion and Adhesives, 29, 2009, 621-632.

9. Desai S.D., Patel J.V. and Sinka V.K. Polyurethane adhesive system from biomaterial-based polyol for bonding wood. International Journal of Adhesion and Adhesives, 23, 2003, 393-399.

10. DIN EN 1465. Adhesives. Determination of tensile lap-shear strength of bonded joints.

11. Godzimirski J., Kozakiewicz J., Łunarski J. and Zielecki W. Konstrukcyjne połączenia klejowe elementów metalowych w budowie maszyn. Oficyna Wydawnicza Politechniki Rzeszowskiej, Rzeszów, 1997.

12. Grant L.D.R., Adams R.D. and da Silva L.F.M. Effect of the temperature on the strength of adhesively bonded single lap and $\mathrm{T}$ joints for the auto- motive industry, International Journal of Adhesion and Adhesives, 29, 2009, 535-524.

13. Hass P., Kläusler O., Schlegel S. and Niemz P. Effects of mechanical and chemical surface preparation on adhesively bonded wooden joints. International Journal of Adhesion and Adhesives, 51, 2014, 95-102.

14. http://www.loctite.co.uk (access on 31-05-2017).

15. https://www.bijlard.com (access on 31-05-2017).

16. Pizzi A.Advanced Wood Adhesive Technology. Marcel Dekker, New York, 1994.

17. River B.H. Fracture of adhesive-bonded wood joints. In: Handbook of adhesive technology, revised and expanded, ed. A Pizzi, KL Mittal, Marcel Dekker, Switzerland, 2003.

18. Rudawska A., Danczak I., Müller M. and Valsek P. The effect of sandblasting on surface properties for adhesion. International Journal of Adhesion and Adhesives, 70, 2016, 176-190.

19. Rudawska A. Pressure during curing and the strength of 2024, 2017A and 1050 aluminium alloy sheet adhesive joints. Advances in Science and Technology Research Journal, 9(26), 2015, 96 -103.

20. Rudawska A. Surface free energy and 7075 aluminium bonded joint strength following degreasing only and without any prior treatment. Journal Adhesion Science and Technology, 26, 2012, 1233-1247.

21. Rudawska A. Influence of the thickness of joined elements on lap length of aluminium alloy sheet bonded joints. Advances in Science and Technology Research Journal, 9(27), 2015, 35-44.

22. Serrano E. Adhesive Joints in Timber Engineering. Modelling and Testing of Fracture Properties. Division of Structural Mechanics, Lund University, LUND, Sweden, 2000.

23. Świć A., Draczew A. and Gola A. Method of achieving accuracy of thermo-mechanical treatment of low-rigidity shafts, Advances in Science and Technology Research Journal, 10(29), 2016, 62-70.

24. Veigel S., Müller U., Keckes J., Obersriebnig M. and Gindl-Almutter W. Cellulose nanofibrils as filler for adhesives: effect on specific fracture energy of solid wood-adhesive bonds. Cellulose, 18, 2011, 1227, doi:10.1007/s10570-011-9576-1. 